\title{
A 4-layer Concentrated Winding for a Permanent Magnet Synchronous Motor
}

\author{
Hae-Joong Kim, Youn Hwan Kim, Jae-Won Moon \\ Rotating Machinery Center / Korea Testing Certification \\ 22 Heungan-daero 27beon-gil, Gunpo-si, Korea \\ motor@ktc.re.kr; younhwan@ktc.re.kr; moon@ktc.re.kr
}

\begin{abstract}
Fractional three-phase permanent magnet synchronous machines are becoming more and more attractive solutions for low speed, high torque applications for domestic appliances, automotive, aerospace or wind power generation. However, it is known that these windings, due to the low number of slots/pole/phase, are characterized by high magnetomotive force (MMF) space harmonic content. Fractional slot multilayer windings are allowed to reduce the harmonic component of the windings magneto motive force. The aim of this paper is to present the turn ratio of multilayer (4-layer) three-phase windings which reduces the amplitude of the sub-space harmonics of the MMF. The low order sub-harmonics of the MMF caused by the armature reaction affect the performance degradation of the motor such as eddy current loss in the permanent magnet and a vibration problem. In order to reduce the sub-space harmonics amplitude of the MMF, the optimum turn ratio in the four layer winding should be determined. by calculation of the winding factor, the optimum turn ratio can be found. The sub-space harmonics of the MMF are reduced or eliminated by decision of the turn ratio in four layers. The models with different turn ratio are analyzed based on a comparison of the local force of the stator with harmonic analysis. Two examples of three phase concentrated windings are presented and analyzed as primitive windings, 9slots/8poles and 10slots/12poles.
\end{abstract}

Keywords: Concentrated Winding, Electrical machine, Fractional-Slot, Multiple-layer, Turn ratio.

\section{Introduction}

Recently fractional slot (FS) concentrated windings are often being used in small permanent magnet brushless machines as well as in AC servomotors due to their short end windings. However low speed applications always need electrical machines with high number of poles in both cases of motors and generators. In conventional wound machines the high pole number normally leads to a high slot number implying the disadvantage of a low slot filling factor and increasing the cost of manufacturing. The alternative of fractional slot winding is being considered in such application due to the simplicity of the winding manufacturing and reducing the amount of copper by less end winding length [1], [2]. Usually a winding is arranged so as to realize the maximum winding factor for the main harmonic. Typically single layer and double layer windings, i.e. with one or two layers, are considered in the literature. Even though the various solutions exhibit a similar winding factor for the main harmonic, they exhibit different characteristics since their magneto-motive force (MMF) harmonic content is different. As a result, their performance is also different. In order to reduce the amplitude of the MMF harmonics, it is possible to increase the number of layers and, to determine the turn ratio in the winding [3], [4]. The aim of this paper is to present a turn ratio of multilayer (4-layer) three-phase windings which reduces the amplitude of the sub-space harmonics of the MMF. The low order sub-harmonics of the MMF, which is caused by the armature reaction affects the performance degradation of the motor such as the eddy current loss in the permanent magnet and the vibration problem [2]. In order to reduce the sub-space harmonics amplitude of the MMF, the optimum turn ratio in the four layer winding should be determined. From calculation of the winding factor, the optimum turn ratio can be found. The sub-space harmonics of the MMF are reduced or eliminated by the decision of the turn ratio in four layers. Additionally, the local force harmonic component according to the turn ratio is analyzed with four layers.

\section{Layout of A Multi-Layer Windings}

The ratio $S / t$ for the 9 slot 8 pole is an odd number. The number of spokes in the positive sectors differs by 1 with respect to the spokes number in the negative sector. Each phase contains three alternating adjacent coil, indicating that the periphery of the armature is divided in three equal zones where the three phases have coils. The fundamental space harmonic has the order $v=4$ and, due to the uniform slotting, there will always exist the $S \pm p$ order space harmonics with the same winding 
factors. This makes it impossible to cancel the space harmonics of order $v=5,13,14 \ldots$, etc. Usually there will be the odd space harmonics of orders $v=1,7,11 \ldots$, etc. as well as the even space harmonics of orders $v=2,8,10 \ldots$, etc.

It is possible to shift the sectors in two different ways. In the first case, fig. 1(a), the shift angle is equal to the angle between the two spokes. The second possibility is shown in fig. 1(b). The shift angle is equal to half the angle between the two spokes [3]. The coil $\mathrm{Na}, \mathrm{Nb}$ and $\mathrm{Nc}$ from the top part of the group wound around the teeth has the turn ratio $\mathrm{R} 1=\mathrm{Nb} / \mathrm{Na}$, $\mathrm{R} 2=\mathrm{Nc} / \mathrm{Na}$. The electric angles between the two adjacent spokes are 40o. From the star of the coils as shown in fig. 1, the winding factor $\mathrm{kw}$ of the first case for three-phase 9 slots 8pole 4-layer winding machine is

$$
k_{w}=\frac{1+R_{1} \cos (\pi-v \beta)+R_{2} \cos \{2(\pi-v \beta)\}}{1+R_{1}+R_{2}} \sin \left(\frac{v \beta}{2}\right) \quad \beta=\frac{2 \pi p}{s}, \quad R_{1}=\frac{N_{b}}{N_{a}}, \quad R_{2}=\frac{N_{c}}{N_{a}}
$$

Where, $\beta$ is the slot angle, $p$ is the pole pairs, and $s$ is the slot numbers, $v$ is the space harmonic order, $N_{a}, N_{b}, N_{c}$ is the number of windings on $\mathrm{a}, \mathrm{b}, \mathrm{c}$ phase, $\mathrm{R}$ is the turn ratio.

The winding factor $\mathrm{k}_{\mathrm{w}}$ of second case is

$$
k_{w}=\frac{\left(1+R_{1}\right) \cos \left\{\frac{1}{2}(\pi-v \beta)\right\}+R_{2} \cos \left\{\frac{3}{2}(\pi-v \beta)\right\}}{1+R_{1}+R_{2}} \sin \left(\frac{v \beta}{2}\right)
$$
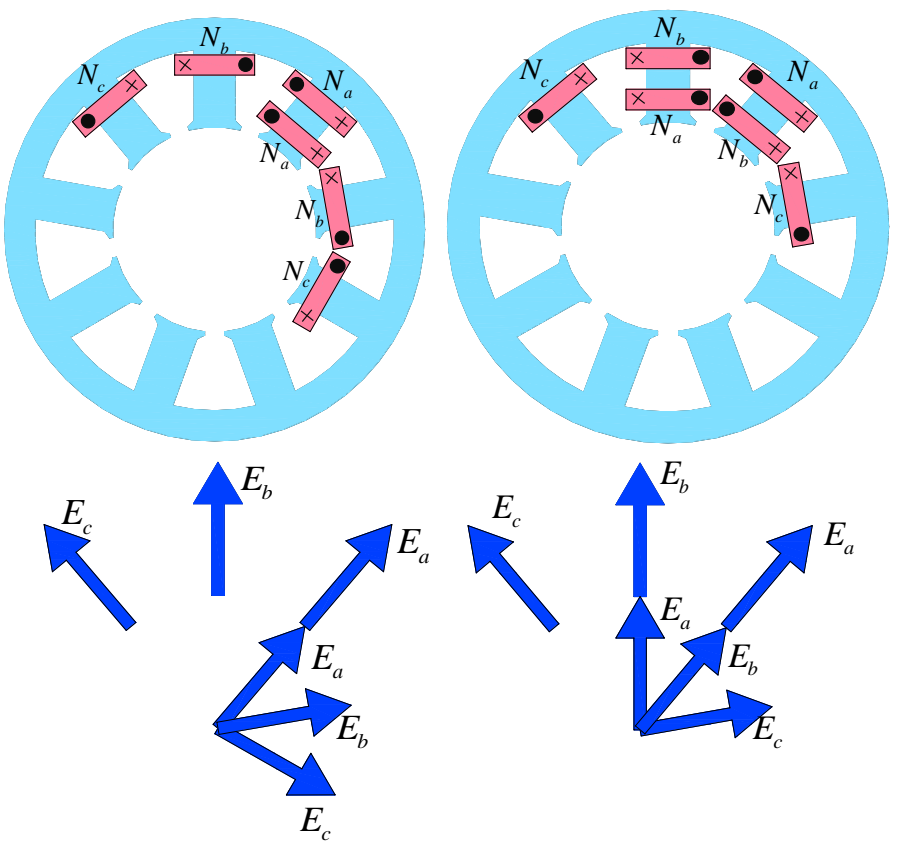

(a) First case of 4-layer winding

(b) Second case of 4-layer winding

Fig. 1: 4-layer windings for the 9slot 8pole. 
Table 1: Winding Factors for 9 Slot 8 Pole 4-Layer Windings.

\begin{tabular}{|c|c|c|c|c|c|c|c|}
\hline \multicolumn{4}{|c|}{ First Case } & \multicolumn{5}{c|}{ Second Case } \\
\hline $\mathrm{R}_{1}=1, \mathrm{R}_{2}=0.79$ & \multicolumn{2}{c|}{$\mathrm{R}_{1}=1, \mathrm{R}_{2}=1.48$} & \multicolumn{2}{c|}{$\mathrm{R}_{1}=1.43, \mathrm{R}_{2}=0.57$} & \multicolumn{2}{c|}{$\mathrm{R}_{1}=1.15, \mathrm{R}_{2}=0.85$} \\
\hline $\mathrm{v}$ & $\mathrm{k}_{\mathrm{w}}$ & $\mathrm{v}$ & $\mathrm{k}_{\mathrm{w}}$ & $\mathrm{v}$ & $\mathrm{k}_{\mathrm{w}}$ & $\mathrm{v}$ & $\mathrm{k}_{\mathrm{w}}$ \\
\hline 1 & 0.000 & 1 & 0.059 & 1 & 0.000 & 1 & 0.031 \\
\hline 2 & 0.139 & 2 & 0.000 & 2 & 0.047 & 2 & 0.000 \\
\hline 3 & 0.937 & 3 & 0.920 & 3 & 0.913 & 3 & 0.897 \\
\hline 4 & 0.937 & 4 & 0.920 & 4 & 0.913 & 4 & 0.897 \\
\hline 5 & 0.139 & 5 & 0.000 & 5 & 0.047 & 5 & 0.000 \\
\hline 6 & 0.000 & 6 & 0.059 & 6 & 0.000 & 6 & 0.031 \\
\hline
\end{tabular}

In fig. 2, the winding factor according to the results of adjusting the turn ratio for the 9 slot 8pole 4-layer winding is presented. One can see that there is a turn ratio point for canceling the winding factor of the space harmonic.

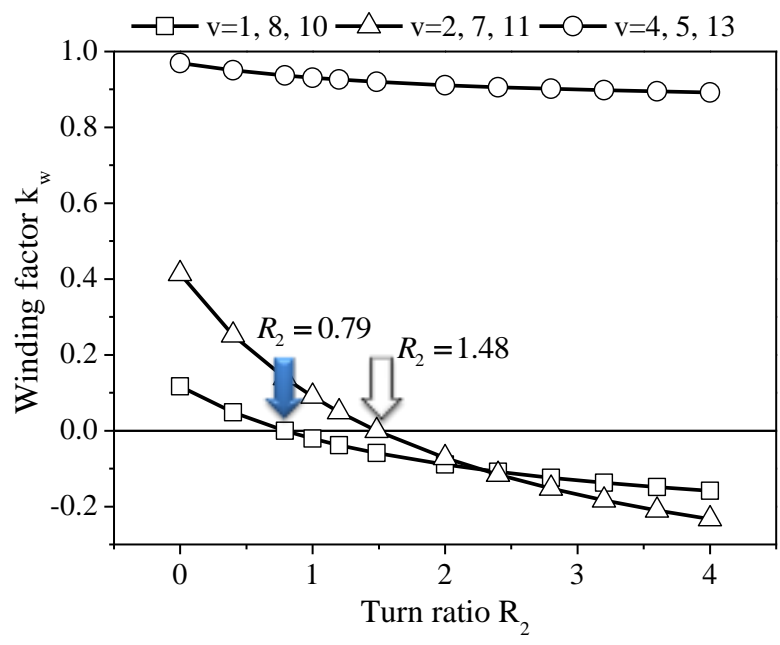

(a) First case of 4-layer winding

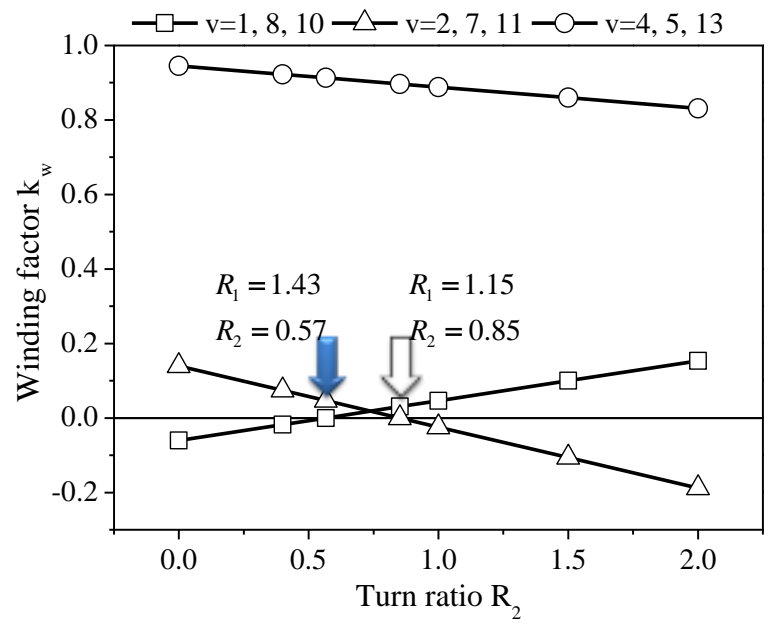

(b) Second case of 4-layer winding

Fig. 2: Winding factor for 9 slot 8pole 4-layer winding.

\section{Examples of Application}

A harmonic analysis of the radial the force was achieved to look for main frequency that influences the noise and vibration. In fig. 3, one can be seen that by introducing the turn ratio of the 4-layer winding, the harmonics for the normal force are reduced for 9 slot 8 pole combinations. This reduction in the harmonic order for normal force is expected to reduce the deformation of the stator in the machine, thereby improving machine noise and vibration.

\section{Conclusion}

The fractional tooth concentrated windings have sub-space harmonics in the MMF of armature reaction because of very low value of the number of slots/pole/phase. In the paper turn ratios are presented to reduce or even to cancel some of the space harmonics of the armature reaction based on decreasing the winding factors. The effectiveness of each turn ratios on vibration reduction is concluded. In the full paper, three types of concentrated windings are analyzed as 9slots/8poles 4-layer winding case I and case II. 


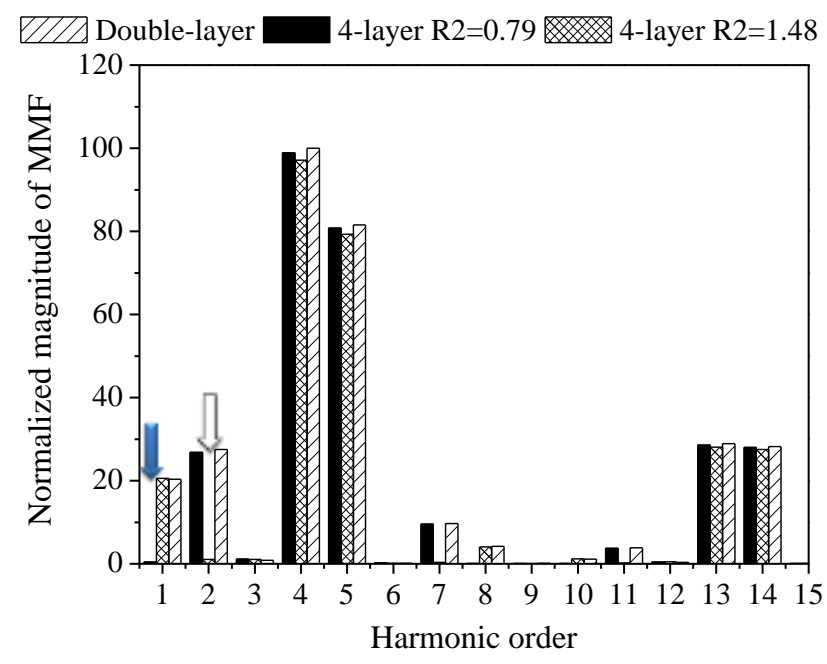

(a) First case of 4-layer winding

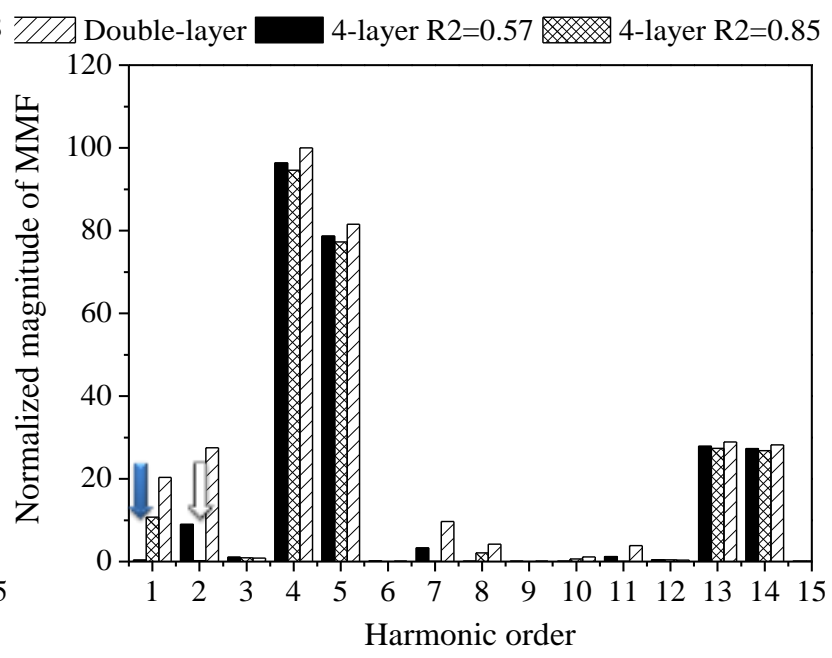

(b) Second case of 4-layer winding

Fig. 3: Normal force spectrum for 9 slot 8pole 4-layer winding.

\section{Acknowledgements}

This work was supported in part by the Korea Institute of Energy Technology Evaluation and Planning under Project 20172010105710 and in part by the Ministry of Trade, Industry and Energy in 2017.

\section{References}

[1] M. V. Cistelecan, F. J. T. E. Ferreira, and M. Popescu, "Three phase tooth-concentrated multiple-layer fractional windings with low space harmonic content," in 2010 IEEE Energy Conversion Congress and Exposition (ECCE), 2010, pp. $1399-1405$.

[2] F. Magnussen and C. Sadarangani, "Winging factors and joule losses of permanent magnet machines with concentrated windings," in proc. IEEE IEMDC, Madison, WI, Jun. 2003, pp. 333-339.

[3] Luigi Alberti, Bicola Bianchi, "Theory and Design of Fractional-Slot Multilayer Windings" in 2011 IEEE Energy Conversion Congress and Exposition (ECCE), 2011, pp. 3112 -3119.

[4] N. Bianchi, S. Bolognani, M. D. Pre, and G. Grezzani, "Design considerations for fractional-slot winding configurations of synchronous machines," IEEE transactions on industry applications, vol. 42, pp. 997-1006, Jul. 2006. 